\title{
Optimizing endothelin receptor antagonist use in the management of pulmonary arterial hypertension
}

\author{
M Kathryn Steiner \\ loana R Preston ${ }^{2}$ \\ 'Pulmonary Critical Care \\ Unit, Department of Medicine, \\ Massachusetts General Hospital, \\ Boston, MA, USA; ${ }^{2}$ Pulmonary Critical \\ Care and Sleep Division, Department \\ of Medicine, Tufts Medical Center, \\ Boston, MA, USA
}

\begin{abstract}
Endothelin receptor antagonism has emerged as an important therapeutic approach in pulmonary arterial hypertension (PAH). Bench to bedside scientific research has shown that endothelin-1 (ET-1) is overexpressed in several forms of pulmonary vascular disease and may play an important pathogenetic role in the development and progression of PAH. Oral endothelin receptor antagonists (ERAs) improved exercise capacity, functional status, pulmonary hemodymanics, and delayed the time to clinical worsening in several randomized placebocontrolled trials. Two ERAs are currently approved by the US Food and Drug Administration: bosentan, a dual ERA for patients with class III and IV PAH, and ambrisentan, a selective ERA for patients with class II and III PAH. Sitaxsentan, another selective ERA, has been approved in Europe, Canada, and Australia. The objective of this review is to evaluate the available evidence describing the pharmacology, efficacy, safety, and tolerability, and patient-focused perspectives regarding the different types of endothelin receptor antagonists. Ongoing and forthcoming randomized trials are also highlighted including the approach of combining this class of drugs with other drugs that target different cellular pathways believed to be etiologically important in PAH.
\end{abstract}

Keywords: ambrisentan, bosentan, endothelin receptor antagonists, pulmonary arterial hypertension, sitaxsentan

\section{Introduction to newer approaches to management of pulmonary arterial hypertension}

Since the discovery of endothelin-1 (ET-1) in the late 1980s, scientific research has established that excess synthesis of ET-1 is an important factor in the pathogenesis of pulmonary arterial hypertension (PAH). This led to the development of a class of drugs called endothelin receptor antagonists (ERAs). On the basis of a series of randomized controlled clinical trials, bosentan, ambrisentan, and sitaxsentan are licensed in the United States and/or Europe as monotherapy for patients with PAH in Group 1 World Health Organization (WHO) classification (Table 1).

ET-1 is a potent vasoconstrictor that is overexpressed in the plasma and the lungs of patients with PAH, especially in the remodeled precapillary pulmonary microvasculature which is the site of increased pulmonary vascular resistance in PAH (Giaid et al 1993). Studies suggest that dysregulated proliferation and abnormal apoptosis of endothelial cells are integral to the development of PAH (Voelkel et al 1998; Humbert et al 2004; Michelakis 2006). Indeed, scientific work shows that excess ET-1 levels not only cause significant vasoconstriction, but also result in both the abnormal growth pattern of endothelial cells, smooth muscle cells, fibroblasts, and pericytes and inhibit apoptosis of both smooth muscle cells and endothelial cells (Jankov et al 2006; Shichiri et al 1997). These events may contribute to the ongoing vascular remodeling seen in $\mathrm{PAH}$. 
Table I Pulmonary hypertension, Group I World Health Organization Classification (after Venice 2003)

Group I ${ }^{\mathrm{a}}$
Idiopathic IPAH (IPAH)
Familial PAH (FPAH)
Related to
- Connective tissue diseases
- HIV
- Anortal hypertension ${ }^{\mathrm{b}}$
- Congenital heart diseases
Primary pulmonary hypertension of the newborn (PPHN)
PAH with venule/capillary involvement (pulmonary veno-occlusive
disease, PVOD)
Others: Glycogen storage disease, Gaucher's, hemoglobinopathies
(ie, sickle cell), hereditary hemorrhagic telagiectasia (HHT)
andothelin receptor anagonists have not been studied formally in portal hypertension,
PPHN, PVOD and other types of group I PAH.
${ }^{\mathrm{b} G i v e n}$ the potential for liver toxicity, caution is advised when using these agents in
patients with portal hypertension due to end stage liver disease.

\section{Review of pharmacology, mode of action, pharmacokinetics of endothelin receptor antagonists with specific reference to differential effects of the various agents Mode of action}

ET-1 acts on two G protein-coupled receptors termed $\mathrm{ET}_{\mathrm{A}}$ and $\mathrm{ET}_{\mathrm{B}}$ (Arai et al 1990; Sakurai et al 1990). $\mathrm{ET}_{\mathrm{A}}$ receptors are abundant on smooth muscle, pericytes, and fibroblasts and their activation by ET-1 results in vasoconstriction and proliferation in vitro (Evans et al 1999). $\mathrm{ET}_{\mathrm{B}}$ receptors are present on endothelial cells as well as pulmonary artery smooth muscle cells. Distal lung microvasculature have a greater proportion of $\mathrm{ET}_{\mathrm{B}}$ receptors and the receptor density in distal arteries is twofold greater in pulmonary hypertensive patients compared to normal human pulmonary arteries (Davie et al 2002a). ET-1 activates $\mathrm{ET}_{\mathrm{B}}$ receptors at low doses, whilst at higher doses $\mathrm{ET}_{\mathrm{A}}$ receptors are activated. Both ET-1 receptors mediate smooth muscle cell contraction (McCulloch et al 1996) and proliferation (Davie et al 2002b). In addition, stimulation of $\mathrm{ET}_{\mathrm{B}}$ receptors results in the release of vasodilators and antiproliferative molecules such as prostacyclin and nitric oxide from the endothelium (de Nucci et al 1988), and results in ET-1 clearance from circulation (Dupuis et al 1996a, b). Further animal work has shown that by blocking $\mathrm{ET}_{\mathrm{B}}$ receptors, ET-1 vasoconstrictive activity is enhanced (via the $\mathrm{ET}_{\mathrm{A}}$ receptor), due to inhibition of the transient $\mathrm{ET}_{\mathrm{B}}$ induced vasodilatation and
ET-1 clearance. In other animal models of $\mathrm{PAH}, \mathrm{ET}_{\mathrm{A}}$ receptor blockade decreased the degree of pulmonary hypertension by $25 \%$ with no effect from the $\mathrm{ET}_{\mathrm{B}}$ receptor blockade (Black et al 2003). Conversely, other studies showed that combined $\mathrm{ET}_{\mathrm{A}}$ and $\mathrm{ET}_{\mathrm{B}}$ receptor blockade inhibited ET-1 induced vasoconstriction more effectively than the $\mathrm{ET}_{\mathrm{A}}$ blocker alone (Sato et al 1995) and in monocrotaline-induced pulmonary hypertension, dual ETA/B blockade produced better survival than selective $\mathrm{ET}_{\mathrm{A}}$ blockade (Jasmin et al 2001). Nevertheless, selectively blocking the $\mathrm{ET}_{\mathrm{A}}$ receptors and preserving the vasodilatory and clearance function of the $\mathrm{ET}_{\mathrm{B}}$ receptors may be of benefit in patients where excess synthesis of ET-1 rather than reduced clearance is resulting in excess pulmonary vascular constriction (Langleben et al 2006). However, because there are differences between experimental and clinical forms of PAH and clinical studies have not been performed to address if there are clinically significant differences between dual and selective ERAs, the therapeutic superiority of selective versus combined ET receptor blockade remains unanswered and has been subject to great debate.

Two ERAs are on the US market: bosentan $\left(\right.$ Tracleer $^{\circledR}$, Actelion Pharmaceuticals Ltd, Allschwil, Switzerland) and ambrisentan (Letairis ${ }^{\circledR}$, Gilead Sciences, Foster City, CA, USA). Sitaxsentan (Thelin ${ }^{\circledR}$, Encysive Pharmaceuticals, Houston, Texas, USA) is approved in Canada, Europe, and Australia. Bosentan inhibits both the $\mathrm{ET}_{\mathrm{A}}$ and $\mathrm{ET}_{\mathrm{B}}$ receptors $\left(\mathrm{ET}_{\mathrm{A}}: \mathrm{ET}_{\mathrm{B}} 20: 1\right)$ while ambrisentan $\left(\mathrm{ET}_{\mathrm{A}}: \mathrm{ET}_{\mathrm{B}} 260: 1\right)$ and sitaxsentan $\left(\mathrm{ET}_{\mathrm{A}}: \mathrm{ET}_{\mathrm{B}} 6500: 1\right)$ are selective for the $\mathrm{ET}_{\mathrm{A}}$ receptor (Battistini et al 2006).

\section{Pharmacokinetics}

Bosentan is dosed as $62.5 \mathrm{mg}$ twice a day the first 4 weeks and $125 \mathrm{mg}$ twice a day thereafter (Dingemanse et al 2002a), ambrisentan is dosed 5 or $10 \mathrm{mg}$ once a day (Galie et al 2005; Prod Info Letairis ${ }^{\circledR}$ oral tablets 2007), and sitaxsentan is dosed $100 \mathrm{mg}$ once a day (Barst et al 2006). Unlike bosentan and sitaxsentan, ambrisentan has a propanoic acid structure (Battistini et al 2006). This difference may account for the lack of liver toxicity and/or lack of dug-drug interaction reported with ambrisentan.

\section{Drug concentration levels}

Bosentan administered orally reaches peak concentration within 3 to 5 hours and steady state by $3-5$ days (Dingemanse et al 2002a). Concomitant administration of bosentan and inhibitors of CYP3A4 can increase the peak plasma concentration by more than 2-fold (van Giersbergen et al 2002a). Oral ambrisentan reaches peak concentration within 2 hours 
after administration (Prod Info Letairis ${ }^{\circledR}$ oral tablets 2007) and oral sitaxsentan reaches peak concentration within 1 to 3 hours (Wu et al 2004b).

\section{Absorption}

Bosentan's bioavailability is thought to be $50 \%$ and is similar for $125 \mathrm{mg}$ tablet or with two $62.5 \mathrm{mg}$ tablets (Dingemanse et al 2002b). Ambrisentan is rapidly absorbed after oral administration but the bioavailability is unknown. Food has no effect on the bioavailability of ambrisentan or bosentan. Sitaxsentan's oral bioavailability is greater than $90 \%$ (Widlitz et al 2005).

\section{Distribution}

All three ERAs are highly bound to plasma proteins $(\mathrm{Wu}$ et al 2004b; Dingemanse et al 2002a; Prod Info Letairis ${ }^{\circledR}$ oral tablets 2007).

\section{Metabolism}

Bosentan is extensively metabolized by the liver (Weber et al 1996b). Ambrisentan is a strong inhibitor of P-glycoprotein, organic anion transport protein, cytochrome P450 and uridine 5 diphosphate glucuronosyltransferases UGTs (Prod Info Letairis ${ }^{\circledR}$ oral tablets 2007). Sitaxsentan is a moderate inhibitor of liver cytochrome CYP2C9 (Widlitz et al 2005). It displays nonlinear metabolism at a dose of $300 \mathrm{mg}$, while $100 \mathrm{mg}$ dose has linear metabolism (Barst et al 2004).

\section{Drug-drug interaction}

All three drugs are contraindicated in conjunction with cyclosporine A and glyburide (van Giersbergen et al 2002b; Treiber et al 2007). Bosentan induces warfarin metabolism and requires an increase in the warfarin dose (Murphey and Hood 2003), while sitaxsentan decreases warfarin metabolism, requiring a drop in the warfarin dose (Barst et al 2006). There are no known interactions between ambrisentan and warfarin.

\section{Excretion}

The elimination of bosentan is primarily through the biliary system with only $3 \%$ or less excreted through the kidneys (Weber et al 1996a). The elimination of ambrisentan is mainly by nonrenal pathways and the relative contributions of metabolism and biliary elimination have not been characterized (Prod Info Letairis ${ }^{\circledR}$ oral tablets 2007). Fifty to $60 \%$ of sitaxsentan is eliminated via the urine while the rest is eliminated via the feces (Wu et al 2004b).

\section{Elimination half-life}

The half-life of bosentan is 5-8 hours (Weber et al 1996a). The half-life of ambrisentan is 9-15 hours (Prod Info
Letairis $^{\circledR}$ oral tablets 2007). The half-life of sitaxsentan is 6-7 hours (Wu et al 2004a).

\section{Studies of the various endothelin antagonists in PAH}

Table 2 summarizes the studies discussed in this review.

\section{Bosentan}

A pilot study of 7 patients with $\mathrm{PAH}$ showed that an infusion of high doses of bosentan acutely lowered both pulmonary and systemic vascular resistances (Williamson et al 2000). Several of the patients died or suffered clinical deterioration during the second phase of the study, which may have been related to their poor clinical status. ET-1 levels were elevated, consistent with a concomitant blockade of the endothelial $\mathrm{ET}_{\mathrm{B}}$ receptor.

These data led to the first randomized, double-blind, placebo-controlled 12 week trial to evaluate the clinical effects of bosentan as a long-term oral treatment (Channick et al 2001). Oral bosentan (62.5 mg twice a day for 4 weeks, then $125 \mathrm{mg}$ twice daily) improved exercise capacity (measured by 6-minute walk distance), pulmonary vascular resistance, and WHO functional class in patients with idiopathic PAH or PAH related to scleroderma. All patients had WHO functional class III at baseline. In both groups, more patients had idiopathic PAH than PAH related to scleroderma. The main difference between the groups was the slightly longer duration of disease before the diagnosis in patients assigned placebo than those assigned bosentan. The incidence of hepatotoxicity in bosentan treated patients was $10 \%$ and resolved with discontinuation of the drug.

A 16 week, double blind, placebo-controlled study, the Bosentan Randomized Trial of Endothelin Antagonist Therapy (BREATHE-1) showed that patients treated with oral bosentan (62.5 $\mathrm{mg}$ twice a day for 4 weeks, then either $125 \mathrm{mg}$ or $250 \mathrm{mg}$ twice daily) had improved exercise capacity as measured by the 6-minute walk distance, and functional class, and it delayed time to clinical worsening compared with placebo (Rubin et al 2002). Most patients were in functional class III, with a few in class IV. In both groups, more patients had idiopathic PAH than PAH associated with connective tissue disorders. Subgroup analysis suggested that bosentan improves the walking distance from baseline in patients with idiopathic PAH (46 $\mathrm{m}$ increase as opposed to a $5 \mathrm{~m}$ decline in the placebo group) while bosentan appeared to prevent deterioration in the walking distance only among patients with scleroderma. Abnormal hepatic function was found to be dose dependent. Increases in hepatic transaminase levels to 


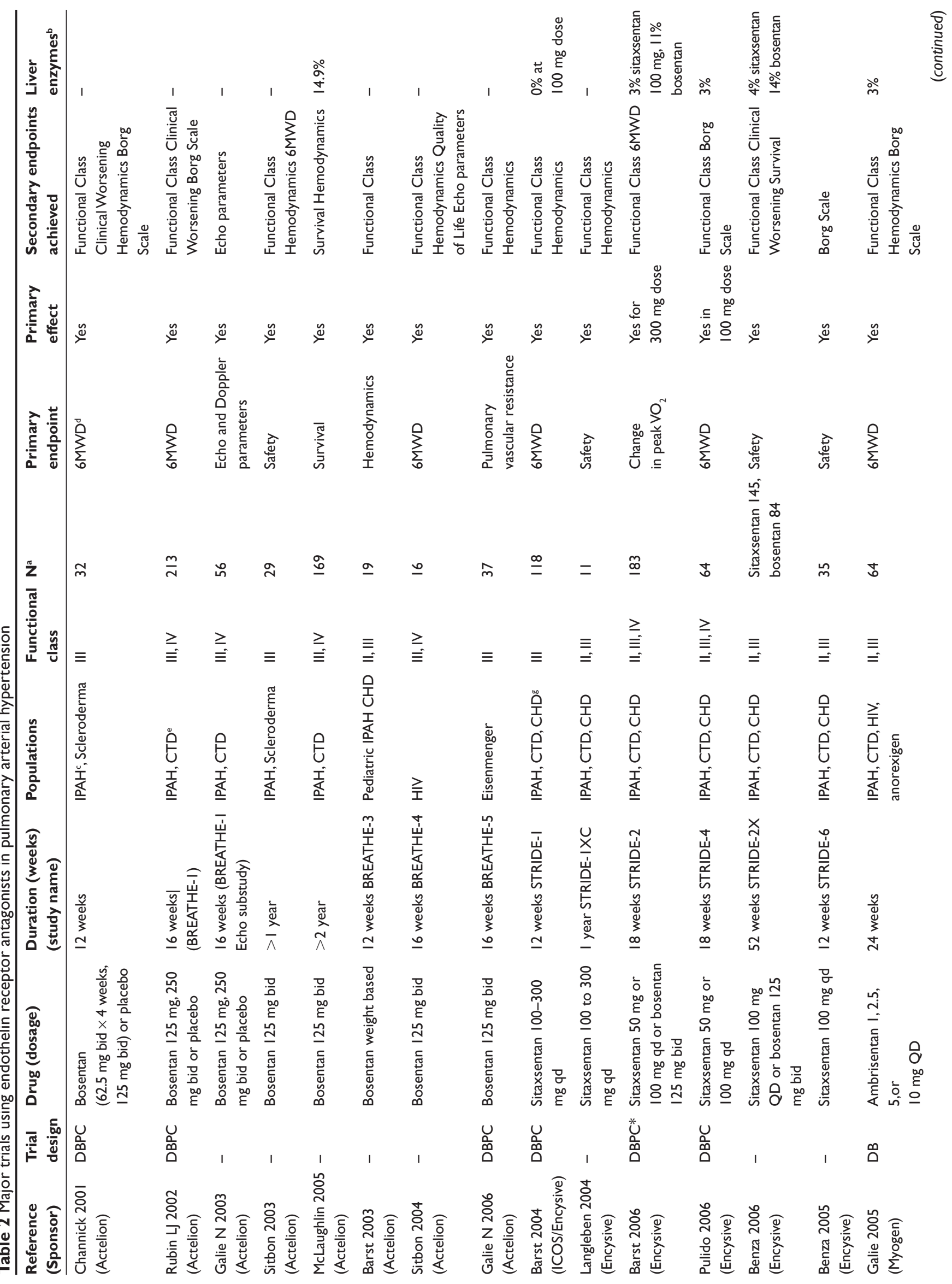




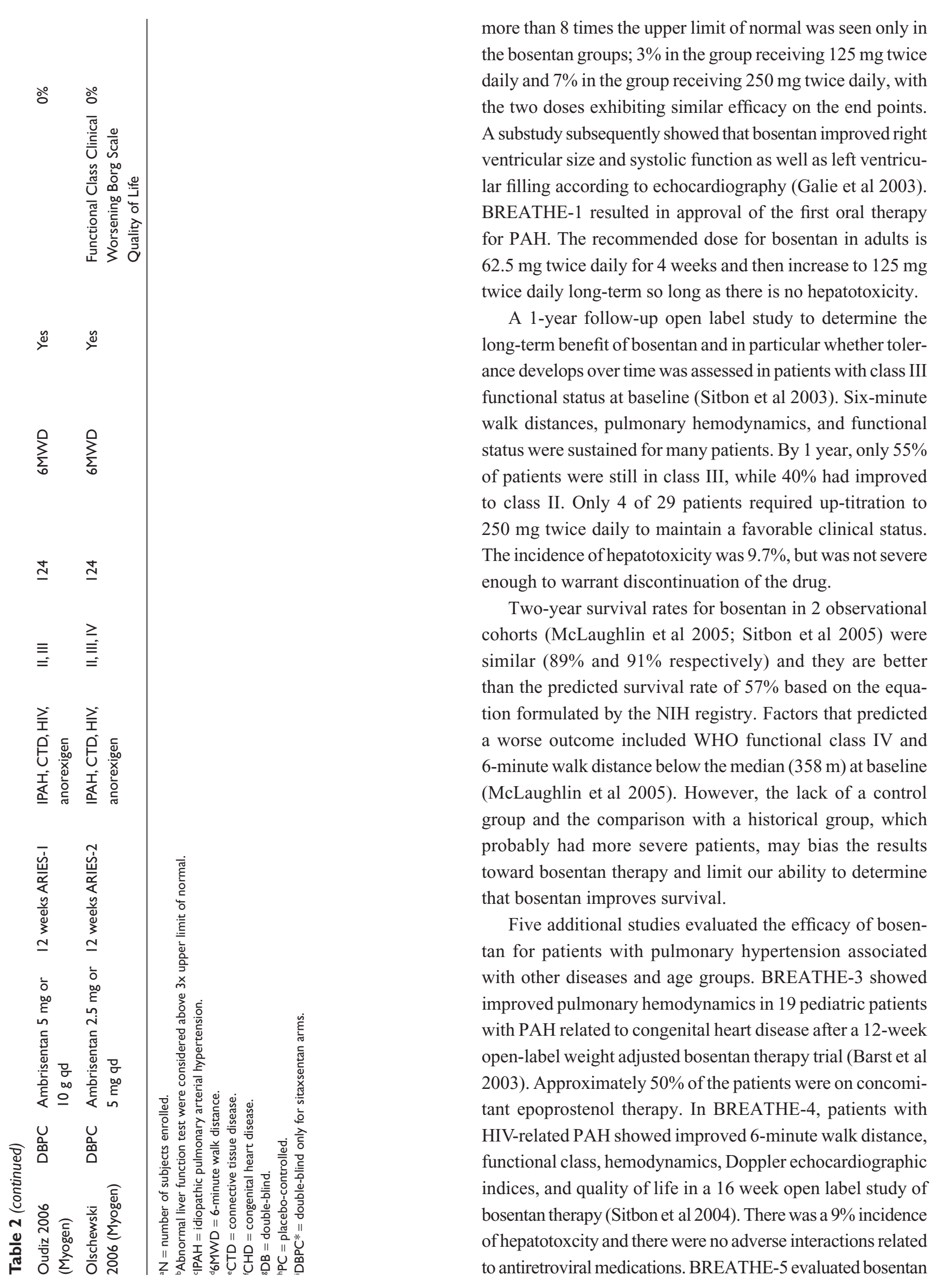

Vascular Health and Risk Management 2008:4(5) 
therapy in 54 patients with class III PAH due to congenital heart disease and Eisenmenger's syndrome in a randomized double blinded placebo controlled study over 16 weeks (Galie et al 2006). Bosentan therapy improved hemodynamics and exercise capacity in these patients.

Bosentan has also shown to improve functional capacity and symptoms in two prospective studies enrolling patients with pulmonary hypertension secondary to inoperable thromboembolic disease (Bonderman et al 2005; Hoeper et al 2005).

\section{Ambrisentan}

Ambrisentan is an endothelin receptor antagonist that is selective for $\mathrm{ET}_{\mathrm{A}}$ with a bioavailability and half-life (9-15 hours) that allows once a day dosing. A 12-week blinded to dose but without a placebo armed study was performed to determine the efficacy and safety of 4 doses in patients with PAH (Galie et al 2005). Patients at all doses (1, 2.5, 5, or $10 \mathrm{mg}$ daily) had improved 6-minute walk distance, functional class, Borg scale, and hemodynamics as compared with baseline. Adverse events were mild and unrelated to dose, including the $3 \%$ incidence of elevated hepatic transaminases of $>3 x$ the upper limit of normal. Subgroup analysis showed that patients with idiopathic PAH appeared to have a dose-response relationship for the 6-minute walk distance.

In a phase III, randomized, double-blinded, placebocontrolled, multicenter, efficacy study of ambrisentan in subjects with PAH (ARIES-1), 202 patients were randomly assigned to $5 \mathrm{mg}$ or $10 \mathrm{mg}$ of ambrisentan or placebo once daily. There were significant improvements in 6-minute walk distance, functional class, Borg dyspnea score, and quality life score (Oudiz et al 2006). In ARIES-2, patients with PAH were randomly assigned to placebo, ambrisentan $2.5 \mathrm{mg}$, or ambrisentan $5 \mathrm{mg}$ once daily over 12 weeks (Olschewski et al 2006). There were also significant improvements in 6-minute walk distance and a delay to clinical worsening. No significant adverse events occurred including no interaction with warfarin therapy, nor did any patient develop elevated hepatic transaminases above $3 \mathrm{x}$ the upper limit of normal.

\section{Sitaxsentan}

Sitaxsentan was evaluated in an open-label pilot study to determine the safety and efficacy of 12 weeks of therapy on exercise capacity and hemodynamics in children and adults with idiopathic PAH, and associated diseases of PAH such as congenital heart disease and collagen vascular disease (Barst et al 2002). The study demonstrated significant increases in 6-minute walk distances and improved hemodynamics in patients who had functional class II, III, and IV PAH at doses between 100 to $500 \mathrm{mg}$ twice daily. In the extension phase, 2 patients had severe hepatitis resulting in 1 death despite stopping the drug. The hepatic toxicity is related to the non-linear pharmacokinetics of sitaxsentan at high doses and thus subsequent studies have used doses up to $300 \mathrm{mg}$ once a day.

This lead to STRIDE-1, the first randomized doubleblinded placebo-controlled trial using lower doses of Sitaxsentan (100 mg and $300 \mathrm{mg}$ ) and administering it only once daily for 12 weeks. STRIDE-1 included patients with idiopathic $\mathrm{PAH}$ and associated $\mathrm{PAH}$ diseases such as congenital heart disease and connective tissue disease and had no ceiling on the 6-minute walk distance, allowing patients with less severe PAH to be enrolled. STRIDE-1's primary endpoint was peak oxygen consumption on the cardiopulmonary exercise testing and the results showed only an improvement in the percent of predicted peak oxygen consumption in the $300 \mathrm{mg}$ group compared with placebo. This index was subsequently found to have interhospital variability, and thus its use in multi-center trials is questionable (Oudiz et al 2006). However, the secondary endpoints 6-minute walk distance, WHO functional class, and pulmonary hemodynamics all improved significantly at both $100 \mathrm{mg}$ and $300 \mathrm{mg}$ doses. The most frequently reported clinical adverse events with sitaxsentan treatment were headache, peripheral edema, nausea, nasal congestion, and dizziness. The most frequently reported laboratory adverse event was increased international normalized ratio or prothrombin time, related to the effect of sitaxsentan on inhibition of CYP2C9 P450 enzyme, the principal enzyme involved in the metabolism of warfarin (Barst et al 2002). The incidence of elevated hepatic transaminases above three times the upper limit of normal was $0 \%$ at $100 \mathrm{mg}$ dose and $10 \%$ at the $300 \mathrm{mg}$ dose. However, by 26 weeks in the extension study (STRIDE-1X) there was a $5 \%$ incidence of elevated transaminases with the $100 \mathrm{mg}$ dose and $21 \%$ incidence with the $300 \mathrm{mg}$ dose.

A post-hoc subgroup analysis was performed on 42 patients who had $\mathrm{PAH}$ associated with connective tissue disease out of the 178 patients enrolled in STRIDE-1 (Girgis et al 2007). Those patients treated with $100 \mathrm{mg}$ or $300 \mathrm{mg}$ of sitaxsentan had significant improvements in their 6-minute walk distance (a mean of $58 \mathrm{~m}$ placebo-subtracted treatment effect, $p=0.027$ ), quality of life, and hemodynamics. Sitaxsentan appears to be tolerated well with only two patients that developed elevation of hepatic transaminases. A 1-year follow-up STRIDE-1 study, revealed that eleven 
PAH patients tolerated $100 \mathrm{mg}$ of sitaxsentan daily well with sustained improvement in functional class, pulmonary vascular resistance, and cardiac output (Langleben et al 2004).

An 18-week, double-blinded study compared sitaxsentan at $50 \mathrm{mg}$ or $100 \mathrm{mg}$ to placebo or open label bosentan (62.5 mg twice daily for 4 weeks and then $125 \mathrm{mg}$ twice daily) (STRIDE-2) (Barst et al 2006). The $100 \mathrm{mg}$ sitaxsentan and the bosentan arms, but not the $50 \mathrm{mg}$ sitaxsentan arm, showed significant and similar improvements in 6-minute walk distance and functional class. The incidence of elevated hepatic transaminases $(>3 \mathrm{x}$ the upper limit of normal) was $3 \%$ for $100 \mathrm{mg}$ sitaxsentan, 5\% for $50 \mathrm{mg}$ sitaxsentan, 11\% for bosentan, and $6 \%$ for placebo. STRIDE-4 is another study comparing $50 \mathrm{mg}$ with $100 \mathrm{mg}$ dose of sitaxsentan and placebo in Latin America, Poland, and Spain, which enrolled mostly patients in NYHA functional class II (Pulido et al 2006). The $100 \mathrm{mg}$ dose improved 6-minute walk distance, functional class, Borg dyspnea scale, and time to clinical worsening, while the $50 \mathrm{mg}$ dose did not. Interestingly, however, the placebo groups also had a significant improvement in 6-minute walk distance by $34 \mathrm{~m}$. This placebo improvement effect is thought to be due to the perception of improved medical care after enrollment among patients who might not otherwise have had access to that level of care. Patients tolerated sitaxsentan well with only 1 patient in each group developing elevated hepatic transaminases. In the STRIDE-2X extension open-label study (Benza et al 2006), patients who initially received $50 \mathrm{mg}$ of sitaxsentan were given $100 \mathrm{mg}$ and those who were on placebo were either assigned to $100 \mathrm{mg}$ of sitaxsentan daily or $125 \mathrm{mg}$ twice daily of bosentan, while those patients on either $100 \mathrm{mg}$ of sitaxsentan or $125 \mathrm{mg}$ of bosentan remained on the same therapy. At one year time to clinical worsening and liver function test abnormalities were better in the sitaxsentan group. In addition, the 1-year risk of discontinuation from monotherapy was $25 \%$ for sitaxsentan versus $42 \%$ for bosentan ( $\mathrm{p}=0.003$ ). However, these interpretations should be made with caution, as the study was not powered to detect differences between treatments. STRIDE-3 is a long-term safety trial with over 800 patients enrolled and the results have not been reported yet.

STRIDE-6 (Benza et al 2007) studied the safety and efficacy of sitaxsentan in patients discontinuing bosentan due to hepatotoxicity or inadequate efficacy. After 12 weeks, only 1 of the 12 patients who had previously experienced hepatotoxicity on bosentan developed elevated liver enzymes with sitaxsentan. Five of the 15 (33\%) who discontinued bosentan because of lack of efficiency had an improvement in 6-minute walk distance of more than $115 \%$ while taking sitaxsentan. No long-term data are yet available for this group.

\section{Combination therapy with endothelin receptor antagonists}

Patients' quality of life and survival with PAH still remain poor despite the tremendous medical advances with monotherapy. This has led to attempts to combine different classes of therapies that have different actions such as ERAs with phosphodiesterase-5 inhibitors (eg, sildenafil) or prostanoids (eg, epoprostonol, trepostinil, iloprost, or beraprost). Unfortunately, studies to ascertain what combinations are beneficial and which have potential for adverse drug-drug interactions have not been conducted. A pilot pharmacologic study assessed the combination of bosentan with sildenafil (a phosphodiesterase-5 inhibitor approved for the treatment of PAH) in 10 patients with PAH (Paul et al 2005). Bosentan was given $62.5 \mathrm{mg}$ twice daily for $1 \mathrm{month}$, then $125 \mathrm{mg}$ twice daily for a second month. Sildenafil $100 \mathrm{mg}$ was given before the first bosentan dose and at the end of each month of bosentan treatment. Treatment with bosentan $62.5 \mathrm{mg}$ twice daily was associated with a 2-fold increase in sildenafil clearance. Increasing the dose of bosentan to $125 \mathrm{mg}$ twice daily led to a further increase in sildenafil oral clearance, demonstrating that bosentan decreases the plasma concentration of sildenafil. Preliminary results from the EARLY trial (Rubin et al 2007) looking at 29 patients with mild PAH (WHO functional class II) on sildenafil in whom bosentan was added showed that the addition of bosentan decreased pulmonary vascular resistance by $20 \%$ and a delay to clinical worsening, although there was no improvement in the 6-minute walk distance. A recent study evaluated whether combination therapy after failure of bosentan monotherapy, particularly in patients with scleroderma-associated $\mathrm{PAH}$ (PAH-SSD) was effective. Addition of sildenafil improved New York Heart Association class and 6-min walk distance in idiopathic $\mathrm{PAH}$ patients but failed to improve either parameter in PAH-SSD patients (Mathai et al 2007). Another study evaluated the addition of bosentan in PAH patients already on either inhaled iloprost or oral beraprost, two prostanoids. The addition of bosentan in an open-label fashion resulted in improved 6-minute walk distances after 3 months of combined therapy and the therapy was well tolerated (Hoeper et al 2003). In a 16-week BREATHE-2 study, patients already receiving intravenous epoprostenol had either bosentan or placebo added (Humbert et al 2004). The results were not as promising. Hemodynamics improved but not significantly and there was no improvement in functional class or 
exercise capacity. This study, however, was not powered to detect differences in efficacy. More importantly, there were serious adverse events, including death in the group receiving epoprostenol and bosentan. In the recent (STEP) combination trial, inhaled iloprost or placebo was added to patients receiving bosentan therapy (McLaughlin et al 2006). By week 12, patients receiving bosentan and iloprost had improved their New York Heart Association status by one class and had a delay to clinical worsening compared with those patients who were on bosentan and placebo. Also of note is that the post-inhalation iloprost-bosentan group had improved their pulmonary hemodynamics. A safety and efficacy study (Hoeper et al 2006) of inhaled iloprost in those patients already treated with bosentan was terminated early after a futility analysis revealed that the primary endpoint, change in 6-minute walking distance, failed to show a positive effect of adding inhaled iloprost. Further studies involving larger sample sizes and long-term follow-up are needed to determine the efficacy of adding inhaled iloprost to bosentan in patients with idiopathic PAH.

\section{Transitioning from other PAH therapies to endothelin receptor antagonists}

Transitioning patients onto oral therapy from parental forms of therapy is an attractive goal for our patients with PAH. The first study reported 4 patients with normal hemodynamics on epoprostenol who were successfully transitioned to oral bosentan (Kim et al 2003). A subsequent study evaluated three children who had normal hemodynamics on epoprostenol and showed that these children after having been switched to bosentan remained stable for a full 1-year study period (Ivy et al 2004). However, in subsequent studies that evaluated patients on parental prostanoids that did not normalize their pulmonary hemodynamics prior to adding bosentan, only $75 \%$ transitioned successfully to bosentan and of those that transitioned more than $60 \%$ on bosentan therapy alone deteriorated within 3-16 months after the prostanoids were stopped (Suleman and Frost 2004; Steiner et al 2006). Given the high percentage of patients who deteriorate after they are transitioned to oral ERA therapy and the lack of randomized multicenter controlled trials evaluating the safety and efficacy of transitioning patients, we recommend only transitioning patients from prostaglandins to bosentan in those who have normalized their pulmonary hemodynamics and are under close observation.

\section{Differential safety and tolerability}

Both bosentan and sitaxsentan have been reported to cause hepatic toxicity, while ambrisentan seems to have no effects on the liver. In a post-market analysis of 4,994 patients on bosentan followed up prospectively for 30 months, the incidence of liver function test elevation above 3 times the upper limit of normal was $7.6 \%$, with an annual rate of $10.1 \%$ and a discontinuation rate of $3.7 \%$ (Humbert et al 2007). From the STRIDE trials, the incidence of liver abnormalities with sitaxsentan is approximately $5 \%$ with the $100 \mathrm{mg}$ daily, while ambrisentan does not seem to affect liver function. Nevertheless, all three compounds require monthly monitoring of liver function tests. ERAs are potent teratogens and contraception is required for women with childbearing potential (Spence et al 1999).

\section{Patient-focused perspectives such as quality of life, patient satisfaction, tolerability, adherence, and uptake}

All pivotal studies have shown improvement in functional capacity with ERAs compared with placebo. Only two studies have formerly evaluated patients' quality of life using the SF-36 questionnaire; BREATHE-4 (bosentan in HIV) and ARIES-2 (ambrisentan), both of which showed significant improvement. However, the SF-36 questionnaire which is used in patients with chronic lung disease has not been validated for PAH. Nevertheless, a combination of improvement in functional capacity, coupled with the ease of administration, is a major advantage of this class of therapies. Since placebo control randomized studies assessing survival in PAH patients treated with ERAs have not been performed, it is difficult to ascertain whether these drugs affect survival.

\section{Conclusions, optimizing selection, and use in therapy}

Since the discovery of ET-1 in 1988, and its pivotal role in the pathogenesis of $\mathrm{PAH}$, endothelin receptor antagonist therapies have emerged, improving the lives of many patients with PAH. For patients with Group 1 PAH with a negative vasoreactivity test and NYHA class II-IV, non-selective endothelin receptor antagonist bosentan improves hemodynamics, exercise capacity and delays clinical worsening. There is published experience with bosentan in various subgroups of

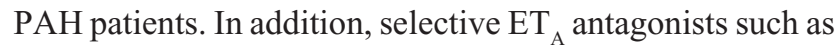
ambrisentan and sitaxsentan also improve exercise tolerance, 
functional class, hemodynamics, and quality of life. To date, we lack comparative clinical studies to evaluate whether selective inhibition has a clinical advantage over nonselective inhibition. From the current data we know that the safety profiles and the drug-drug interactions are different for the different ERAs. Although monthly liver test monitoring is required for all three drugs, ambrisentan has the least liver toxicity. Concomitant warfarin therapy with sitaxsentan will require the warfarin dose to be reduced, while with bosentan, the warfarin dose must be increased, and with ambrisentan there is no need to alter the warfarin dose.

Many questions remain unanswered and deserve further study, such as understanding the pharmacogenomics of responders and non-responders to therapy, a better understanding of the importance of selectivity versus nonselectivity, the need for robust survival data, and determining the effective combination therapy. Limited experience suggests that bosentan can be used safely with epoprostenol or treprostinil. The benefits of bosentan plus sildenafil are best described in patients with idiopathic PAH, and less so in sclerodermaassociated PAH. The effect of combining bosentan with iloprost is less clear. Larger trials are underway to investigate the role of combination oral therapies. Despite the ongoing unanswered questions, the rapid translation of basic science into applicable and efficacious therapies for patients with $\mathrm{PAH}$ has had a tremendous impact in caring for these patients.

\section{Disclosures}

Dr Preston has received grants from and is on the speakers' bureau for Actelion and Gilead Pharmaceuticals.

\section{References}

Arai H, Hori S, Aramori I, et al. 1990. Cloning and expression of a cDNA encoding an endothelin receptor. Nature, 348:730-2.

Barst RJ, Ivy D, Dingemanse J, et al. 2003. Pharmacokinetics, safety, and efficacy of bosentan in pediatric patients with pulmonary arterial hypertension. Clin Pharmacol Ther, 73:372-82.

Barst RJ, Langleben D, Badesch D, et al. 2006. Treatment of pulmonary arterial hypertension with the selective endothelin-A receptor antagonist sitaxsentan.[see comment]. J Am Coll Cardiol, 47:2049-56.

Barst RJ, Langleben D, Frost A, et al. 2000. Sitaxsentan therapy for pulmonary arterial hypertension. Am J Resp Crit Care Med, 169:441-7.

Barst RJ, Rich S, Widlitz A, et al. 2002. Clinical efficacy of sitaxsentan, an endothelin-A receptor antagonist, in patients with pulmonary arterial hypertension: open-label pilot study. Chest, 121:1860-8.

Battistini B, Berthiaume N, Kelland NF, et al. 2006. Profile of past and current clinical trials involving endothelin receptor antagonists: the novel "sentan" class of drug. Exp Biol Med (Maywood), 231:653-95.

Benza RL, Frost A, Girgis RE, et al. 2006. Chronic treatment of pulmonary arterial hypertension with sitaxsentan and bosentan [abstract]. Proc Am Thorac Soc, 3:A729.

Benza RL, Mehta S, Keogh A, et al. 2007. Sitaxsentan treatment for patients with pulmonary arterial hypertension discontinuing bosentan. $J$ Heart Lung Transplant, 26:63-9.
Black SM, Mata-Greenwood E, Dettman RW, et al. 2003. Emergence of smooth muscle cell endothelin B-mediated vasoconstriction in lambs with experimental congenital heart disease and increased pulmonary blood flow. Circulation, 108:1646-54.

Bonderman D, Nowotny R, Skoro-Sajer N, et al. 2005. Bosentan therapy for inoperable chronic thromboembolic pulmonary hypertension. Chest, 128:2599-603.

Channick RN, Simonneau G, Sitbon O, et al. 2001. Effects of the dual endothelin-receptor antagonist bosentan in patients with pulmonary hypertension: a randomised placebo-controlled study. Lancet, 358:1119-23.

Davie N, Haleen SJ, Upton PD, et al. 2002a. ET(A) and ET(B) receptors modulate the proliferation of human pulmonary artery smooth muscle cells. Am J Respir Crit Care Med, 165:398-405.

Davie N, Haleen SJ, Upton PD, et al. 2002b. ET(A) and ET(B) receptors modulate the proliferation of human pulmonary artery smooth muscle cells. Am J Resp Crit Care Med, 165:398-405.

de Nucci G, Thomas R, D’Orleans-Juste P, et al. 1988. Pressor effects of circulating endothelin are limited by its removal in the pulmonary circulation and by the release of prostacyclin and endothelium-derived relaxing factor. Proc Natl Acad Sci USA, 85:9797-800.

Dingemanse J, Bodin F, Weidekamm E, et al. 2002a. Influence of food intake and formulation on the pharmacokinetics and metabolism of bosentan, a dual endothelin receptor antagonist. J Clin Pharmacol, 42:283-9.

Dingemanse J, Bodin F, Weidekamm E, et al. 2002b. Influence of food intake and formulation on the pharmacokinetics and metabolism of bosentan, a dual endothelin receptor antagonist. J Clin Pharmacol, 42:283-9.

Dupuis J, Goresky CA, Fournier A. 1996a. Pulmonary clearance of circulating endothelin-1 in dogs in vivo: exclusive role of ETB receptors. J Appl Physiol, 81:1510-5.

Dupuis J, Stewart DJ, Cernacek P, et al. 1996b. Human pulmonary circulation is an important site for both clearance and production of endothelin1. Circulation, $94: 1578-84$.

Evans AM, Cobban HJ, Nixon GF. 1999. ET(A) receptors are the primary mediators of myofilament calcium sensitization induced by ET-1 in rat pulmonary artery smooth muscle: a tyrosine kinase independent pathway. Br J Pharmacol, 127:153-60.

Galie N, Badesch D, Oudiz R, et al. 2005. Ambrisentan therapy for pulmonary arterial hypertension. J Am Coll Cardiol, 46:529-35.

Galie N, Beghetti M, Gatzoulis MA, et al. 2006. Bosentan therapy in patients with Eisenmenger syndrome: a multicenter, double-blind, randomized, placebo-controlled study. Circulation, 114:48-54.

Galie N, Hinderliter AL, Torbicki A, et al. 2003. Effects of the oral endothelin-receptor antagonist bosentan on echocardiographic and doppler measures in patients with pulmonary arterial hypertension. $J \mathrm{Am}$ Coll Cardiol, 41:1380-6.

Giaid A, Yanagisawa M, Langleben D, et al. 1993. Expression of endothelin-1 in the lungs of patients with pulmonary hypertension. $N$ Engl $J$ Med, 328:1732-9.

Girgis RE, Frost AE, Hill NS, et al. 2007. Selective endothelinA receptor antagonism with sitaxsentan for pulmonary arterial hypertension associated with connective tissue disease. Ann Rheum Dis, 66:1467-72.

Hoeper MM, Kramm T, Wilkens H, et al. 2005. Bosentan therapy for inoperable chronic thromboembolic pulmonary hypertension. Chest, 128:2363-67.

Hoeper MM, Leuchte H, Halank M, et al. 2006. Combining inhaled iloprost with bosentan in patients with idiopathic pulmonary arterial hypertension. Eur Respir J, 28:691-94.

Hoeper MM, Taha N, Bekjarova A, et al. 2003. Bosentan treatment in patients with primary pulmonary hypertension receiving nonparenteral prostanoids. Eur Respir J, 22:330-4.

Humbert M, Barst RJ, Robbins IM, et al. 2004. Combination of bosentan with epoprostenol in pulmonary arterial hypertension: BREATHE-2. Eur Respir J, 24:353-9. 
Humbert M, Morrell NW, Archer SL, et al. 2004. Cellular and molecular pathobiology of pulmonary arterial hypertension. J Am Coll Cardiol, 43:13S-24S.

Humbert M, Segal ES, Kiely DG, et al. 2007. Results of European postmarketing surveillance of bosentan in pulmonary hypertension. Eur Respir J, 30:338-44.

Ivy DD, Doran A, Claussen L, et al. 2004. Weaning and discontinuation of epoprostenol in children with idiopathic pulmonary arterial hypertension receiving concomitant bosentan. Am J Cardiol, 93:943-6.

Jankov RP, Kantores C, Belcastro R, et al. 2006. Endothelin-1 inhibits apoptosis of pulmonary arterial smooth muscle in the neonatal rat. Pediatr Res, 60:245-51.

Jasmin JF, Lucas M, Cernacek P, et al. 2001. Effectiveness of a nonselective $\mathrm{ET}(\mathrm{A} / \mathrm{B})$ and a selective ET(A) antagonist in rats with monocrotalineinduced pulmonary hypertension. Circulation, 103:314-8.

Kim NH, Channick RN, and Rubin LJ 2003. Successful withdrawal of long-term epoprostenol therapy for pulmonary arterial hypertension. Chest, 124:1612-5.

Langleben D, Dupuis J, Langleben I, et al. 2006. Etiology-specific endothelin-1 clearance in human precapillary pulmonary hypertension. Chest, 129:689-95.

Langleben D, Hirsch AM, Shalit E, et al. 2004. Sustained symptomatic, functional, and hemodynamic benefit with the selective endothelin. A receptor antagonist, sitaxsentan, in patients with pulmonary arterial hypertension: a 1-year follow-up study. Chest, 126:1377-81.

McCulloch KM, Docherty CC, Morecroft I, et al. 1996. EndothelinB receptor-mediated contraction in human pulmonary resistance arteries. Br J Pharmacol, 119:1125-30.

McLaughlin VV, Oudiz RJ, Frost A, et al. 2006. Randomized study of adding inhaled iloprost to existing bosentan in pulmonary arterial hypertension. Am J Respir Crit Care Med, 174:1257-63.

McLaughlin VV, Sitbon O, Badesch DB, et al. 2005. Survival with first-line bosentan in patients with primary pulmonary hypertension. [erratum Eur Respir J, 2005 25:942]. Eur Respir J, 25:244-9.

Mathai SC, Girgis RE, Fisher MR, et al. 2007. Addition of sildenafil to bosentan monotherapy in pulmonary arterial hypertension. Eur Respir J, 29:469-75.

Michelakis ED. 2006. Spatio-temporal diversity of apoptosis within the vascular wall in pulmonary arterial hypertension: heterogeneous BMP signaling may have therapeutic implications. Circ Res, 98:72-5.

Murphey L, Hood E 2003. Bosentan and warfarin interaction. Ann Pharmacother, 37:1028-31.

Olschewski H, Galie N, Kramer M, et al. 2006. Ambrisentan improves exercise capacity and time to clinical worsening in patients with pulmonary arterial hypertension: results of the ARIES-2 study [abstract]. Proc Am Thorac Soc, 3:A278.

Oudiz R, Torres F, Frost A, et al. 2006. ARIES-1: A placebo controlled, efficacy and safety study of ambrisentan in patients with pulmonary arterial hypertension. Chest, 130:121S.

Oudiz RJ, Barst RJ, Hansen JE, et al. 2006. Cardiopulmonary exercise testing and six-minute walk correlations in pulmonary arterial hypertension. Am J Cardiol, 97:123-6.

Paul GA, Gibbs JS, Boobis AR, et al. 2005. Bosentan decreases the plasma concentration of sildenafil when coprescribed in pulmonary hypertension. Br J Clin Pharmacol, 60:107-12.

Pulido T, Kurzyna M, Souza R, et al. 2006. Sitaxsentan $100 \mathrm{mg}$ proves more effective than sitaxsentan $50 \mathrm{mg}$ patients with pulmonary arterial hypertension [abstract]. Proc Am Thorac Soc, 3:A417.

Rubin JL, Simonneau G, Hoeper MM, et al. 2007. Bosentan improves hemodynamics in patients receiving backgroundsildenafil treatment: results from EARLY, a randomized, double-blind, placebo-controlled study in patients with mildly symptomatic pulmonary arterial hypertension [abstract]. Chest, 132:487S.

Rubin LJ, Badesch DB, Barst RJ, et al. 2002. Bosentan therapy for pulmonary arterial hypertension. [erratum $N$ Engl $J$ Med, 2002 346:1258]. N Engl J Med, 346:896-903.
Sakurai T, Yanagisawa M, Takuwa Y, et al. 1990. Cloning of a cDNA encoding a non-isopeptide-selective subtype of the endothelin receptor. Nature, 348:732-5.

Sato K, Oka M, Hasunuma K, et al. 1995. Effects of separate and combined ETA and ETB blockade on ET-1-induced constriction in perfused rat lungs. Am J Physiol, 269:L668-672.

Shichiri M, Kato H, Marumo F, et al. 1997. Endothelin-1 as an autocrine/ paracrine apoptosis survival factor for endothelial cells. Hypertension, 30:1198-203.

Sitbon O, Badesch DB, Channick RN, et al. 2003. Effects of the dual endothelin receptor antagonist bosentan in patients with pulmonary arterial hypertension: a 1-year follow-up study. Chest, 124:247-54.

Sitbon O, Gressin V, Speich R, et al. 2004. Bosentan for the treatment of human immunodeficiency virus-associated pulmonary arterial hypertension. Am J Respir Crit Care Med, 170:1212-7.

Sitbon O, McLaughlin VV, Badesch DB, et al. 2005. Survival in patients with class III idiopathic pulmonary arterial hypertension treated with first line oral bosentan compared with an historical cohort of patients started on intravenous epoprostenol. Thorax, 60:1025-30.

Spence S, Anderson C, Cukierski M, et al. 1999. Teratogenic effects of the endothelin receptor antagonist L-753,037 in the rat. [erratum Reprod Toxicol, 1999 13:237]. Reprod Toxicol, 13:15-29.

Steiner MK, Preston IR, Klinger JR, et al. 2006. Conversion to bosentan from prostacyclin infusion therapy in pulmonary arterial hypertension: a pilot study. Chest, 130:1471-80.

Suleman N, Frost AE. 2004. Transition from epoprostenol and treprostinil to the oral endothelin receptor antagonist bosentan in patients with pulmonary hypertension. Chest, 126:808-15.

Treiber A, Schneiter R, Hausler S, et al. 2007. Bosentan is a substrate of human OATP1B1 and OATP1B3: inhibition of hepatic uptake as the common mechanism of its interactions with cyclosporin A, rifampicin, and sildenafil. Drug Metab Dispos, 35:1400-7.

van Giersbergen PL, Halabi A, Dingemanse J. 2002a. Single- and multipledose pharmacokinetics of bosentan and its interaction with ketoconazole. Br J Clin Pharmacol, 53:589-95.

van Giersbergen PL, Treiber A, Clozel M, et al. 2002b. In vivo and in vitro studies exploring the pharmacokinetic interaction between bosentan, a dual endothelin receptor antagonist, and glyburide. Clin Pharmacol Ther, 71:253-62.

Voelkel NF, Cool C, Lee SD, et al. 1998. Primary pulmonary hypertension between inflammation and cancer. Chest, 114:225S-30S.

Weber C, Schmitt R, Birnboeck H, et al. 1996a. Pharmacokinetics and pharmacodynamics of the endothelin-receptor antagonist bosentan in healthy human subjects. Clin Pharmacol Ther, 60:124-37.

Weber C, Schmitt R, Birnboeck H, et al. 1996b. Pharmacokinetics and pharmacodynamics of the endothelin-receptor antagonist bosentan in healthy human subjects. Clin Pharmacol Ther, 60:124-37.

Widlitz AC, Barst RJ, Horn EM. 2005. Sitaxsentan: a novel endothelin. A receptor antagonist for pulmonary arterial hypertension. Expert Rev Cardiovasc Ther, 3:985-91.

Williamson DJ, Wallman LL, Jones R, et al. 2000. Hemodynamic effects of bosentan, an endothelin receptor antagonist, in patients with pulmonary hypertension. Circulation, 102:411-8.

Wu C, Decker ER, Blok N, et al. 2004a. Discovery, modeling, and human pharmacokinetics of $\mathrm{N}$-(2-acetyl-4,6-dimethylphenyl)3-(3,4-dimethylisoxazol-5-ylsulfamoyl) thio phene-2-carboxamide (TBC3711), a second generation, ETA selective, and orally bioavailable endothelin antagonist. J Med Chem, 47:1969-86.

Wu C, Decker ER, Blok N, et al. 2004b. Discovery, modeling, and human pharmacokinetics of N-(2-acetyl-4,6-dimethylphenyl)3-(3,4-dimethylisoxazol-5-ylsulfamoyl)thiophene-2-carboxamide (TBC3711), a second generation, ETA selective, and orally bioavailable endothelin antagonist. J Med Chem, 47:1969-86. 